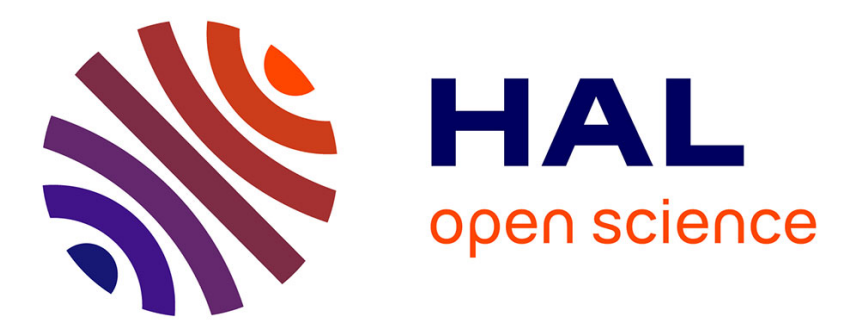

\title{
Studying Students' Learning Processes Used During Physics Teaching Sequence About Gas With Networks of Ideas and Their Domain of Applicability
}

Damien Givry, Andrée Tiberghien

\section{- To cite this version:}

Damien Givry, Andrée Tiberghien. Studying Students' Learning Processes Used During Physics Teaching Sequence About Gas With Networks of Ideas and Their Domain of Applicability. International Journal of Science Education, 2012, pp.223-249. 10.1080/09500693.2011.566289 . hal00704666

\section{HAL Id: hal-00704666 \\ https://hal.science/hal-00704666}

Submitted on 6 Jun 2012

HAL is a multi-disciplinary open access archive for the deposit and dissemination of scientific research documents, whether they are published or not. The documents may come from teaching and research institutions in France or abroad, or from public or private research centers.
L'archive ouverte pluridisciplinaire HAL, est destinée au dépôt et à la diffusion de documents scientifiques de niveau recherche, publiés ou non, émanant des établissements d'enseignement et de recherche français ou étrangers, des laboratoires publics ou privés. 


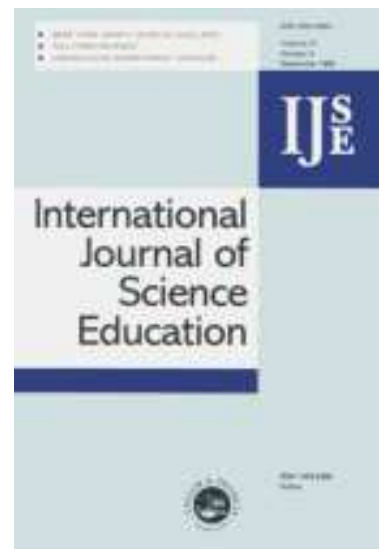

Studying Students' Learning Processes Used During Physics Teaching Sequence About Gas With Networks of Ideas and Their Domain of Applicability

\begin{tabular}{|r|l|}
\hline Journal: & International Journal of Science Education \\
\hline Manuscript ID: & TSED-2010-0342-A \\
\hline Manuscript Type: & Research Paper \\
\hline Keywords : & student, conceptual development, physics education \\
\hline Keywords (user): & Video analysis, Students' Learning Processes, expressed ideas \\
\hline \multicolumn{2}{|l}{} \\
\hline
\end{tabular}

\section{SCHOLARONE}

Manuscripts 
"If you study many people with a questionnaire, you could learn a lot about the questionnaire.
If you study the same person in many situations, you could probably learn more about the person"

Since the late 1970s there have been major efforts in physics education research to identify students' ideas that differ from the standard view of physics. There is currently an enormous body of literature providing evidence of students' conceptions in different scientific domains, such as: physics, chemistry, biology, mathematics or medicine (e.g., Pfundt \& Duit, 2010). This body of literature also demonstrates the robustness of students' conceptions in the face of efforts to change them. Based on Kuhn's theory of changes in sciences and Piaget's notion of accommodation, a central study formalised four conditions to describe the conceptual change of students' initial conceptions towards a scientifically correct one (Posner, Strike, Hewson \& Gertzog, 1982). A revisionist theory of conceptual change was then envisaged in terms of conceptual ecology (Strike \& Posner, 1992) to improve these conditions. Different models have been proposed for describing the conceptual change students undergo (e.g. Brown \& Hammer, 2008; Chi, 2008; DiSessa, 1993; 2008; Hewson, 2008; Hewson \& Hewson, 1992; Vosniadou \& Brewer, 1992; S. Vosniadou, Vamvakoussi, \& Skopeliti, 2008). In the same way, other research studies suggested improving analyses about conceptual change by taking account of news components, such as: motivation (e.g. Pintrich, 1999), affective (e.g. Pintrich, Marx, \& Boyle 1993; Zembylas, 2005), metacognition (e.g. Adey, 1999; Gunstone \& Mitchell, 1998; White, 1993) or sociocultural aspects (e.g. Miyake, 2008; Sinatra \& Mason, 2008; Wiser \& Smith, 2008).

All these studies shared the common point that most conceptual changes are a gradual and slow process, even if they often vary in the way of inducing change and modelling students' knowledge (e.g. Caravita \& Hallden, 1994; Hatano \& Inagaki, 1994; Vosniadou, 2003; Wiser \& Smith, 2008; Vosniadou, Vamvakoussi \& Skopeliti, 2008). Furthermore, some studies specify that radical conceptual change in the long term depends on the micro changes in the short term (Vosniadou, 1994).

Micro change is also called process by several studies. In that way, Clement (2008, p.433) started to paint an overview of the different kinds of processes involved in several studies on conceptual change. He 
illustrated some processes to describe conceptual change, such as: concept differentiation or integration (Wiser \& Carey, 1983), abstraction (Gentner, 1983; Holyoak \& Thagard, 1989), synthesis of two models (Vosniadou \& Brewer, 1992), change of the domain of applicability (DiSessa, 1988; Smith, DiSessa \& Rochelle, 1994) etc. The process, which consists of 'establishing links between conceptions' (also called networks by Minstrell, 1992), is missing in this overview. However, it is described by several studies through: (a) the coordination classes composed by the links between P-prims (DiSessa \& Sherin, 1998), (b) the network of interrelationships among facets (Minstrell, 1992) and (c) the level of complexity of which the higher levels (area IV) describe co-variations of more than two variable properties (Aufschnaiter \& Aufschnaiter, 2003).

Among these different processes, our study proposes to focus on two processes to describe some aspects of students' learning during a physics teaching sequence. These processes are based on the notions of domain of applicability (Balacheff, 1999; DiSessa, 1988; Minstrell, 1992) and network of ideas (DiSessa \& Sherin, 1998; Minstrell, 1992; Aufschnaiter \& Aufschnaiter, 2003).

In the same way, our study needs to collect data continuously (e.g. with video recording) during the teaching sequence to be able to capture and describe these learning processes involved for students (Duit, Goldberg \& Niedderer, 1992). Indeed, interviews and questionnaires can only describe some states of students' learning (e.g. before and after teaching or at different steps of a teaching sequence), without giving information about what happens between two states.

\section{Idea, Domain of Applicability and Network of Ideas}

Our theoretical background adopts a socio-constructivist approach and uses tools coming from discourse analysis to study students' learning. Our study considers learning as situated (Lave \& Wenger, 1991) and distributed (Hutchins, 1995). In that way, we define learning as 'increasing the possibility to act'. However, our present study focuses only upon acts of communication. Especially on the ideas expressed by students 
through oral and written language, to identify specific learning processes involved during a teaching sequence.

In that way, we need to adopt students' points of view to reconstruct ideas expressed by them. That requires avoiding misconception approaches, which assess students' answers as 'correct' or 'incorrect' with regard to the standard physics views. Furthermore, our study attempts to reconstruct the meaning-making expressed by students during teaching, without making any hypotheses on mental structures located somewhere in the mind of students, e.g.: mental model (DiSessa, 2002; Minstrell, 1992; Vosniadou, Vamvakoussi, \& Skopeliti, 2008), cognitive process (Aufschnaiter \& Aufschnaiter, 2003) or internal structures (Reiss \& Tunnicliffe, 2001). The aim of this approach is to minimise the risks of over-interpretation, by making hypotheses on the meaning expressed by students based on available semiotic resources, instead of attempting to model inaccessible hidden mental structures. The general argument is that we do not know what happens in the students' brain but we have easy access to their discourse (e.g. Edwards, 1993; Givry \& Roth, 2006; Lemke, 1990; Saljo, 1999). We consider that, even if the points of view on the students' mind modelling are different, the analysis and the results on learning could be compatible and mutually reinforced.

To summarise, our study proposes to analyse some students' learning processes by trying to adopt students' points of view, without any judgement with regard to views on science. That necessitates reconstructing students' ideas based on the meaning expressed by them during communication, without attempting to reconstruct mental structures located in their mind. Consequently, we define an idea as an unit of analysis of all relevant semiotic (meaning-making) resources publicly made available by a speaker through oral or written communication. In this way, a person can express an idea through: (a) different semiotic registers (text, graph, drawing, formula etc.) by writing (Duval, 1995) or (b) different semiotic resources (talk, gesture, salient elements of the setting) contained in discourse (Givry \& Roth, 2006). 
Our current study focuses on talk, gesture and salient elements of the setting based on previous studies which demonstrate that students' speech cannot be understood without the contribution of gestures and salient elements in the setting (e.g. Givry \& Roth, 2006; Goodwins, 2000; McNeil, 1985). These different modalities (talk, gesture and salient element) convey the whole meaning but in different and irreducible ways. The term gesture refers to spontaneous movements of the hand(s) accompanying speech, which are idiosyncratic (without specific forms) and are produced without conscious attention (McNeil, 1985). We make the distinction between: Gesture (semiotic hand movements), which appears during communication and manipulation (ergotic hand movements), which operates on objects during an experiment (Givry, 2003). The perceptually salient elements in the setting is a term understood as arising from 'a dynamic, temporally, unfolding process accomplished through the ongoing rearrangement of structures, in the talk, participants' bodies, relevant artefacts, spaces, and features of the material surround that are the focus of the participants' scrutiny' (Goodwin, 2000, p. 1519).

In short, an idea is a researcher's reconstruct of the meaning expressed by a person through talk, gesture and salient elements. Each person is able to express a set of ideas which could (or not) be contradictory between themselves from his/her own point of view or from a researcher's point of view (Balacheff, 1999). Each person can establish links between several ideas through language. These linked ideas are defined as a network of ideas (DiSessa, 1988; Minstrell, 1992). Each idea (or network of ideas) could be expressed in several specific situations. This set of situations is defined as the domain of applicability (Balacheff, 1999; DiSessa, 1988; Minstrell, 1992).

This definition needs to clarify what a situation is and when it changes. A situation is defined by the task stipulated to people. We characterise it by the question asked to students and the experimental equipment available to them. Consequently, a new situation appears when at least the question or one of the elements of the experimental equipment changes. E.g.: a new question with the same experimental equipment or the same 
question with different experimental equipment or a new question with new experimental equipment, etc. In the same way, the same situation (same question and same experimental equipment) can appear at different times during the teaching sequences. Consequently, the stability of an idea (or network of ideas) can be analysed: over time (Petri \& Niedderer, 1998) or across situations (Givry, 2003). This stability depends on the domain of applicability, which could vary from a single situation to a considerable number of situations.

The notion of an expressed idea allows us to describe two learning processes (or micro changes), which consist of: (a) establishing a link between ideas (called a network of ideas) and (b) modifying the domain of applicability. As a matter of fact, we decompose the variation of the domain of applicability of an idea (or network of ideas) into two distinct learning processes. The first process consists of 'increasing the domain of applicability' of an idea (or network of ideas), i.e.: when a student expresses the same idea in other situations (i.e. new question or/and new experimental equipment). The second process corresponds to 'decreasing the domain of applicability', i.e.: when the student explicitly realises that an idea (or a network of ideas) already expressed in a specific situation is not suited to this situation and stops using it.

Finally, we propose to study the three following learning processes: (1) 'establishing a link between ideas', (2) 'increasing the domain of applicability' and (2) 'decreasing the domain of applicability'.

\section{Research questions}

The purpose of this study is to propose an approach to analyse in detail students' learning based on expressed ideas, which allows us to study the involvement of three learning processes during teaching. Providing empirical results from a longitudinal study in a French physics classroom, we answer the questions: How to describe the three learning processes based on ideas expressed by students? How are these processes used by students during the teaching sequence? And specifically, how often these processes appear during teaching. 


\section{Research Design}

Our study proposes to analyse in great detail how the three learning processes are used by students during the teaching sequence. To exemplify the points we make, we draw on data sources collected as part of a more wide ranging study (Author, 2003) about the evolution of students' ideas about the nature of gases. In the following, we describe the study to provide a context for the excerpts from the database used in our argument

\section{School Context and Participants}

Based on theoretical approaches about modelling activities (Tiberghien, 1994), a group called Sesames composed by physics teachers and researchers (including both authors) designed several teaching sequences (Tiberghien, Gaidioz \& Vince, 2009). One of them is about gas and was designed to be taught over a onemonth period (6 lessons) for students at upper secondary school level (grade 10 [15-year-old students]) in agreement with the French official curriculum. In this study, the designed sequence about gases was taught in seven classes of French public (state) schools. Two classes with the same teacher were studied in greater depth (questionnaires, videotaped lessons and interviews): one contained a majority of students majoring in language and literacy; the other class consisted mostly of students majoring in science. To achieve a significant data sample, students from different achievement levels-based on the information obtained from the respective teachers - were asked, and agreed to participate.

\section{Teaching Sequence}

In France, physics is taught using two types of lesson each week: the first lesson type called 'Cours' takes place over a one-hour period with the whole class; the second type called 'TP' takes place over a one-hourand-thirty-minute period with only half the students in the class. The teacher repeats TP twice. The teaching sequence about gas consisted of six lessons divided into two Cours and four TP. According to the official curriculum, the purpose of the teaching sequence was to allow students (a) to use macroscopic variables (pressure, volume, temperature and quantity of matter), and (b) describe and explain gas behaviour based on 
interpretations at the microscopic level (e.g.: molecules' collision and velocity). The teaching sequence included four parts': (1) introduction of the microscopic model to describe air contained in an enclosed syringe; (2) use of the microscopic model for describing the mixing of two gases; (3) description of gas behaviour in different situations (compressed in a syringe, heated in a bottle connected to a plastic balloon) with the macroscopic variables and with their interpretations at the microscopic level; and (4) establishment of links between the macroscopic variables. Furthermore, the teaching sequence is based on a socioconstructivist approach with respect to three main dimensions:

1. Modelling activity: By using physics models to support students' understanding, they are encouraged to actively establish links between the world of objects and events and the world of theory and model (Tiberghien, 2000).

2. Semiotic registers: By using different representations of the same concept, such as formulae, tables, drawings, graphs, natural language etc., students develop a deeper understanding by establishing links between the representations (Duval, 1995).

3. Students' conceptions about gas: Using students' pre-instructional conceptions in teaching helps them to develop scientific concepts. The present teaching sequence takes into account previous results on students' conceptions about gas: Students' conceptions on gas: Using students' pre-instructional conceptions in the teaching helps them to develop scientific concept. The present teaching sequence takes account about previous results on students' conceptions on gas: (a) Students attribute macroscopic properties to the microscopic particles, e.g. molecules of water are blue (e.g. Brook, Briggs, \& Driver, 1984; Meheut \& Chomat, 1990; Novick \& Nussbaum, 1978); (b) gas' distribution is not homogeneous, when an action is exerted on gas (Benson, Wittrock, \& Baur, 1993; Méheut, Larcher, Chomat, \& Barboux, 1988); (c) gases have no mass (Séré, 1985; Stavy, 1988), (d) warm air rises inside a closed container (Séré, 1985); (e) gases without movements do not exert any force

\footnotetext{
${ }^{1}$ The teaching sequence is available at URL http://pegase.inrp.fr
} 
(Clough \& Driver, 1986; Séré, 1985); (f) there is only one effect associated to one cause (Viennot, 2001); (g) severable variables on gas do not change simultaneously (de Berg, 1992; Meheut \& Chomat, 1990; Séré, 1985).

\section{Data Collection}

Different types of data sources were collected including videotaped interviews, videotaped lessons in real classrooms and questionnaires sampling student responses to questions about gas behaviour. In total, our database comprises 420 questionnaires, one-hour videotaped interviews with 14 students, 48 hours of classroom video featuring the same 14 students, and approximately 160 worksheets.

Following the precepts of the Learning Process Studies (Niedderer, Goldberg \& Duit, 1992), fourteen students were videotaped continuously during one month (6 lessons) in a classroom with two cameras standing still without anybody behind and four lapel microphones: one microphone for each student during TP lessons (see figure 1), and one microphone for two students during Cours lessons (see figure 2). An additional camera was used to follow the teacher and the unfolding lesson.

\section{$* * * * * * * * * * * * * * * * * * * *[$ Insert Figure 1 about here $] * * * * * * * * * * * * * * * * * * * *$ $* * * * * * * * * * * * * * * * * * * *[$ Insert Figure 2 about here ]}

The same fourteen students were interviewed by the first author prior to and after the teaching sequence during videotaped sessions using still standing cameras without anybody behind them, and 2 lapel microphones: one microphone for the student and the other one for the interviewer.

\section{Video Analysis}

The videotapes were digitised in QuickTime ${ }^{\mathrm{TM}}$ format. A video analysis software Kronos $^{2}$ (Kerguelen, 2001) was used to code in real time on three levels: (1) tasks done by students, (2) teacher's and students' actions (e.g. reading, writing, talking, handling) and (3) spoken words about gas. Based on lexical analysis about the use of words in science and in everyday life, we defined the following list of words potentially pronounced by students to talk about gas: air, gas, vacuum, macroscopic, volume, quantity, temperature,

\footnotetext{
${ }^{2}$ The software can be downloaded from URL: http://www.univ-tlse2.fr/ltc/kronos/.
} 
pressure, pushing, pressing, force, acting, surface, weight, mass, microscopic, molecule, particle, impact, shock, velocity. We transcribed all clips in which at least (a) one word of the list is pronounced by students or the teacher and (b) when students are handling experiments. This previous work allows us to avoid the clips in which students talk about cats and dogs, e.g.: concert, boys etc.

Because, (1) talk and writing cannot be understood without the context in which they are performed (Edwards, 1993) and (2) we never access the whole context as perceived by speakers, we use the notion of 'pertinent context' to analyse students' productions (Kerbrat-Orecchioni, 1996). Pertinent context is defined as the most pertinent contextual elements from the researcher's assessment. In our study, it is composed by participants in the interaction (teacher, students) and the situation defined by (a) the question on which the students are working and (b) the experimental equipment.

We reconstructed (directly from each selected video clip) all the students' ideas on gas expressed by them based on the pertinent context and the semiotic resources contained in talk, gesture, salient elements and written works. Following the precepts of Interaction Analysis (Jordan \& Henderson, 1995), both authors then met repeatedly to view the video clips and to discuss the reconstructed ideas and the processes involved (i.e. establishment of the network of ideas and change in the domain of applicability). The video extracts were discussed in several groups of researchers with different backgrounds: didactics of physics, science of language, didactics of mathematics, and lexicology. Most of the reconstructed idea was analysed by a minimum of two researchers until a common agreement about the interpretation was established. This kind of video analysis was required to make explicit our criteria used to interpret video and to put these criteria in our transcription. Our analysis focuses in great detail upon the three processes involved for two students during the entire teaching sequence on gas. For the current study, 116 video clips were selected. All of them make the learning processes used by both students during the teaching sequence salient. 


\section{Network of ideas, Increasing and Decreasing of the domain of applicability}

In this section, we present our results in terms of four assertions, which we exemplify with examples from our database. The four assertions related to our research question are:

1. The emergence of the network of three ideas is supported by networks of two ideas expressed previously by students during the teaching sequence.

2. Students express more networks of two ideas than networks of three ideas.

3. The process 'increasing the domain of applicability' of an idea (or network of ideas) is very often used by students during the teaching sequence.

4. The process 'decreasing the domain of applicability' of an idea (or network of ideas) is rarely used by students during the teaching sequence.

In the following sections, we present case studies to illustrate each learning process, and give results to support each assertion. Our analyses of the ideas expressed by students reveal many patterns, that are consistent with, and therefore confirm, our assertions. We have several cases to illustrate each process in our video data of the two students' video. We chose the ones that are particularly suited to the didactic function that any argument has in communicating a novel idea to colleagues.

\section{Networks of ideas}

In this section, we discuss the emergence of a network of ideas through students' discourse in a specific situation. Our study considers a network of ideas as being when at least one idea is linked to another one in the same situation, defined by a question and material experiment. We first analyse how a student expresses a network of three ideas in a specific situation and move to a second analysis to describe the emergence of this network of three ideas supported by networks of two ideas previously expressed by the student. Finally, we study all the networks of ideas expressed by both students during the teaching sequence. 
The aim of the first lesson (called TP $\mathrm{n}^{\circ} 1$ ) is to introduce a microscopic model of gas to describe air contained in an enclosed syringe. To support this introduction students have to use a syringe in each question in this lesson. The student expressed a network of three ideas between volume, quantity and molecules of gas during question $n^{\circ} 2$ of activity $n^{\circ} 2$ (see figure 3 ).

*[Insert Figure 3 about here ]

To analyse students' discourse with regard to the context, we define the pertinent context (see methodology) of episode 1 by: (1) the participants called Anne and Ellen by researchers, who have to work together to develop a common answer, (2) the situation defined by: (a) question $\mathbf{n}^{\circ} \mathbf{2}$ about two parts of air with the same mass (figure 4): 'In the balloon, draw a small amount of the air contained in the syringe when there is no action on the piston of the enclosed syringe (case 1). We want to draw a small part of air with the same mass, as with that considered in case 1, when we push on the piston (case 2). Among the three balloons choose one that you think is best suited, and draw the molecules in it' and (b) experimental equipment: a syringe is available on the students' table.

\section{[Insert Figure 4 about here $] * * * * * * * * * * * * * * * * * * * *$}

The correct answer from the physics point of view consists of choosing the balloon with the smaller volume (corresponding to balloon B in figure 4) and to draw the same number of molecules in both cases. Before episode 1, students read the instructions of question 2 and discuss the number of molecules they will show in both cases.

\section{Episode 1:}

Turn 01 Anne : wait a minute, we've already said that [she points to the syringe], it

\footnotetext{
${ }^{3}$ The following transcription conventions are used: ((laughs)) transcriber's comments are enclosed in double parentheses; , coma indicate a small pause about $0,5 \mathrm{~s} ; \mathbf{( 1 . 0 )}$ time in tenth of a second; ((Anne reads)) the molecules underline indicate when different actions are simultaneously: Anne is reading and she is saying simultaneously 'the molecules'; [ ] square brackets indicate gesture or manipulation; - (n-dash) indicates that an utterance or word stopped short before a completion was evident; (?) each word that could not be identified is indicated by a question mark in parentheses; : colon indicates a lengthening of a phoneme by about 0.1 seconds; $\uparrow$ upward jump in pitch.
} 
is the same quantity, erm it is the same volume, the volume is reduced, but the quantity is the same, if it's the same, it means that it will be exactly the same number of at-, erm of molecules

Turn 02 Ellen: yeah

Anne starts her explanation by pointing to the syringe and saying that 'it is the same quantity'. She immediately rectifies her utterance by specifying that she is talking about the volume: 'erm it is the same volume' (line 02 of the turn 01 ). Then, by saying 'the volume is reduced, but the quantity is the same' (line 03 of the turn 01), Anne establishes a link between the volume and the quantity. Based on the pertinent context (especially on the text in the question), we can infer that Anne means that the volume of the closed syringe decreases when we push on the piston (case 2) but the quantity of air inside the syringe is still the same. By saying: 'if it's the same, it means that it will be exactly the same number of at-, erm of molecules', she establishes a second link between the quantity of air (referred to by the word 'it') inside the closed syringe and the number of molecules. We interpret Anne's explanation by a network of three ideas: 'volume of the syringe decreases $<=>$ quantity inside is identical $<=>$ the number of molecules is identical'. The double arrows: ' $<=>$ ' represent the link between two ideas. This previous analysis shows how we use pertinent context and the semiotic resources contained in students' discourse to reconstruct a network of three ideas. We now propose to illustrate the emergence of the network of three ideas supported by networks of two ideas, by giving all reconstructed ideas and networks of ideas expressed previously by Anne about quantity, volume and molecules during the first lesson (figure 5).

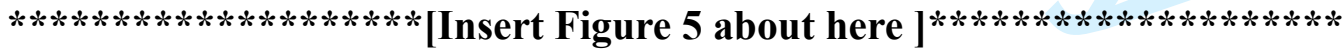

Figure 5 presents ideas designated by a letter: a, b or c and networks of ideas indicated by a number: 1,2 or I. The sign '<=>' represents the link between two ideas. Volume and Quantity are abbreviated in the network by the first letter, $\mathrm{V}$ and $\mathrm{Q}$. We reconstructed the ideas and network of ideas in relation to the time (in brackets) and the different questions in the first lesson called TP $\mathrm{n}^{\circ} 1$. Our analysis identifies that the 
emergence of Anne's network of three ideas comes from two networks of two ideas, that she established previously during this lesson. The link between volume, quantity and number of molecules is established by Anne for the first time around the $31^{\text {st }}$ minute during question 2 of activity 2 (see episode 1 ). Anne firstly establishes the link between the fact that the volume decreases and the quantity is still the same in a closed syringe, shown as a network of ideas (1): $\mathrm{V}$ decreases $<=>\mathrm{Q}$ identical. This network is established around the $19^{\text {th }}$ minute of the session during question 3 of activity 1 (see figure 5). This question 3 asks students to describe what happens to air in a closed syringe at the macroscopic level: without any action on the piston (case 1) and when we push on it (case 2). Then, secondly, Anne establishes the link between the quantity and the number of the molecules (network of ideas (2): 'Q $<=>$ number of molecules'). This link is established around the $26^{\text {th }}$ minute during question 1 of activity 2 , which asks students to show molecules inside a small section of the syringe with the same volume in both cases: when there is no action on the piston and when we push on it.

In the same ways, our analysis shows that the emergence of each network of two ideas is supported by ideas previously expressed by Anne. Indeed, before establishing at 18 minutes and 50 seconds the network of ideas (1) between the volume and the quantity ( $V$ decreases $<=>$ Q identical), Anne expressed at 8 minutes and 26 seconds the idea (a) about the quantity of air into a closed syringe and at 18 minutes 45 seconds the idea (b) about the volume of the syringe. Similarly, Anne expressed the idea (a) and the idea (c) about the number of molecules contained in air before having established the network of ideas (2) between air quantity and the number of molecules.

We did similar analysis of episode 1 in our entire video data to reconstruct all the networks of ideas about gas expressed by students.

Table 1 presents all the networks of ideas reconstructed by researchers during the entire teaching sequence. 


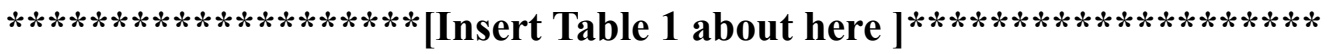

The first column of table 1 indicates the initial of the name of the student who expresses the network of ideas (we quote A \& E, when both students the network of ideas) and the second one gives the name of the network of ideas. In all, we reconstructed 3 networks of three ideas (indicated by roman numerals: I, II etc...) and 16 networks of two ideas (indicated by arabic numerals: 1, 2 etc...): 9 expressed by Anne and 7 used by Ellen. Table 1 shows that networks of three ideas are voiced by only one student, whereas most of the networks of two ideas are established by both students (except networks 5 and 6 only by Anne). This result confirms the assertion: networks of two ideas are expressed more often by students than networks of three ideas during teaching.

For the three networks of three ideas, we can associate two networks of two ideas expressed previously during the teaching sequence (i.e. networks 1 and 2 can be associated to network I and networks 3 and 4 can be related to network II). Network (III) is more complex to analyse than networks I and II ( table 1). Indeed, network (III) necessitates identifying the network of ideas 'Volume of closed syringe increases $<=>$ Number of molecules increases into the closed syringe' (which is the combination of network (5): 'Volume of closed syringe increases $<=>$ Quantity of air into the closed syringe increases' and network (2): 'Quantity of air $<=>$ Number of molecules') and the idea 'molecules take up more space', which probably comes from a sentence from the microscopic model: 'molecules are distributed throughout the volume available to them'. In this case, a network of ideas is linked with an idea, instead of another network of ideas. However, this idea and the network of ideas are expressed by the student previously in the teaching sequence. We consider that they support the emergence of the network (III). Consequently, this result confirms our assertions: The emergence of the networks of three ideas are supported by networks of two ideas expressed previously by the student in the teaching sequence. 


\section{Increasing the domain of applicability}

In this section, we discuss the students' use of the process 'increasing the domain of applicability' during the teaching sequence. This micro-change appears when an idea (or a network of ideas) already applied in a specific situation, is expressed in one or several new situations (i.e. one of the components of the situation changes). Our examples show that the process 'increasing the domain of applicability' is very often used by both students during the entire teaching sequence. We first analyse how a same idea is expressed in three different situations. Secondly, we identify in the whole teaching sequence all the students' use of the process increasing the domain of applicability.

\section{Case study 2: Increasing the domain of applicability of an idea}

Anne increases the domain of applicability of the idea (a) 'air is composed of molecules' by expressing it in two new situations (figure 6). This can be seen across the analysis of three episodes from the first three lessons of the teaching sequence.

$* * * * * * * * * * * * * * * * * * * *[$ Insert Figure 6 about here $] * * * * * * * * * * * * * * * * * * * *$

To analyse students' drawings, we define the pertinent context (see methodology) of episode 1 by: (1) the participants: Anne and Ellen have to work together to develop a common answer during the second activity of the first lesson called TP1, (2) the situation 1, defined by: (a) question $\mathbf{n}^{\circ} \mathbf{2}$ : 'show a small amount of air in the syringe with the same volume in two cases: when there is no action on the piston and when we push on it' (see figure 7) and (b) experimental material: a syringe is available to students. Before episode 1, Anne and Ellen read question 2 and discuss the number of molecules they will highlight in two situations.

\section{Episode 1}

Anne and Ellen produce the following drawings of a small amount of air into the syringe in case 1 and 2 (figure 7).

\section{[Insert Figure 7 about here ]}


To understand Anne's drawing, we need to take into account the context of question 2, which asks her to show a small amount of air in the syringe. Consequently, we consider Anne's black circles, which represent a small amount of air, as the idea (a): 'air is composed of molecules'. These circles give us more information, specifically on the inhomogeneous molecule distribution, which has been comprehensively studied in our previous work (Author, 2003). However, we focus only on idea (a) to illustrate the increase of the domain of applicability.

Anne expresses the idea (a) for the first time during the teaching sequence in situation 1 . Then, she uses it in two new situations described in episodes 2 and 3.

Episode 2 happens during the activity 1.2 of the second lesson called TP $\mathrm{n}^{\circ} 2$. Anne and Ellen (participants) have to work together to correct their previous written answers. Situation $\mathbf{2}$ is composed of: (a) question $\mathbf{n}^{\circ}$ 2: 'show a small amount of air and red gas contained in two flasks when we connect them together and justify your answer' (see figure 8) and (b) experimental equipment: a flask of air connected to a flask of red gas and separated by a barrier wall is used by the teacher during the lesson.

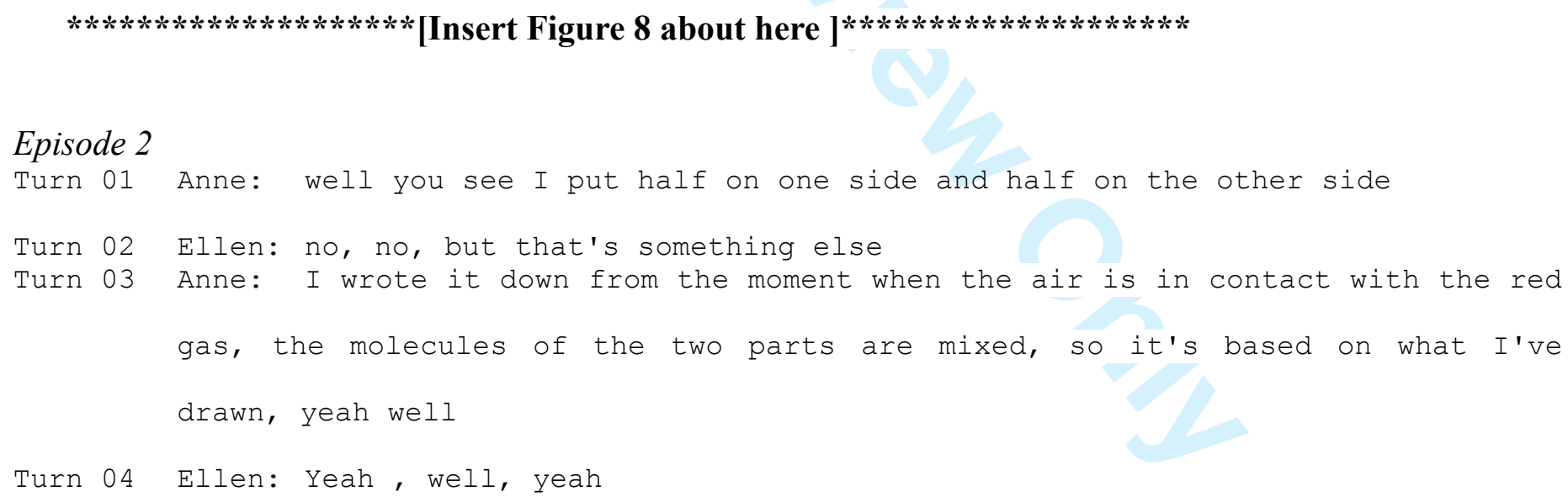

Anne explains the first part of question 2 to Ellen, about the representation of air and red gas in the two flasks connected together (turn 01). However, Ellen wants some information on Anne's written answer (turn 02). Anne explains her written answer by specifying that 'when air is in contact with the red gas, the molecules of the two parts are mixed' (turn 03). With regard to the context, we consider that the term 'two 
parts' expressed by Anne refer to small amounts of air and red gas (see figure 8). Consequently, we reconstruct the idea (a) 'air is composed of molecules' based on Anne's utterance expressed in turn 03. Episode 2 shows how Anne expresses the idea (a) through her speech in situation 2. This situation is new, because the experimental equipment is very different from situation 1. Indeed, situation 1 involves a syringe, whereas situation 2 uses air and red gas contained in two flasks. Expressing the same idea in a new situation illustrates the process increasing the domain of applicability, i.e. increasing the set of situations in which an idea is expressed.

In episode 2 the domain of applicability of the idea (a) is composed from situations 1 and 2. Episode 3 shows how this domain of applicability can be increased by one additional situation. It happens during activity 2 of the third lesson called Cours 1. Four students (Anne, Ellen, Adele and Marie) have to discuss and write a common answer. Situation 3 is defined by: (1) question $\mathbf{n}^{\circ} \mathbf{1}$ : 'give the value of the pressure, when we connect the pressure gauge to the syringe full of air like on figure 9' and (2) experimental equipment is composed by a syringe connected to a pressure gauge.

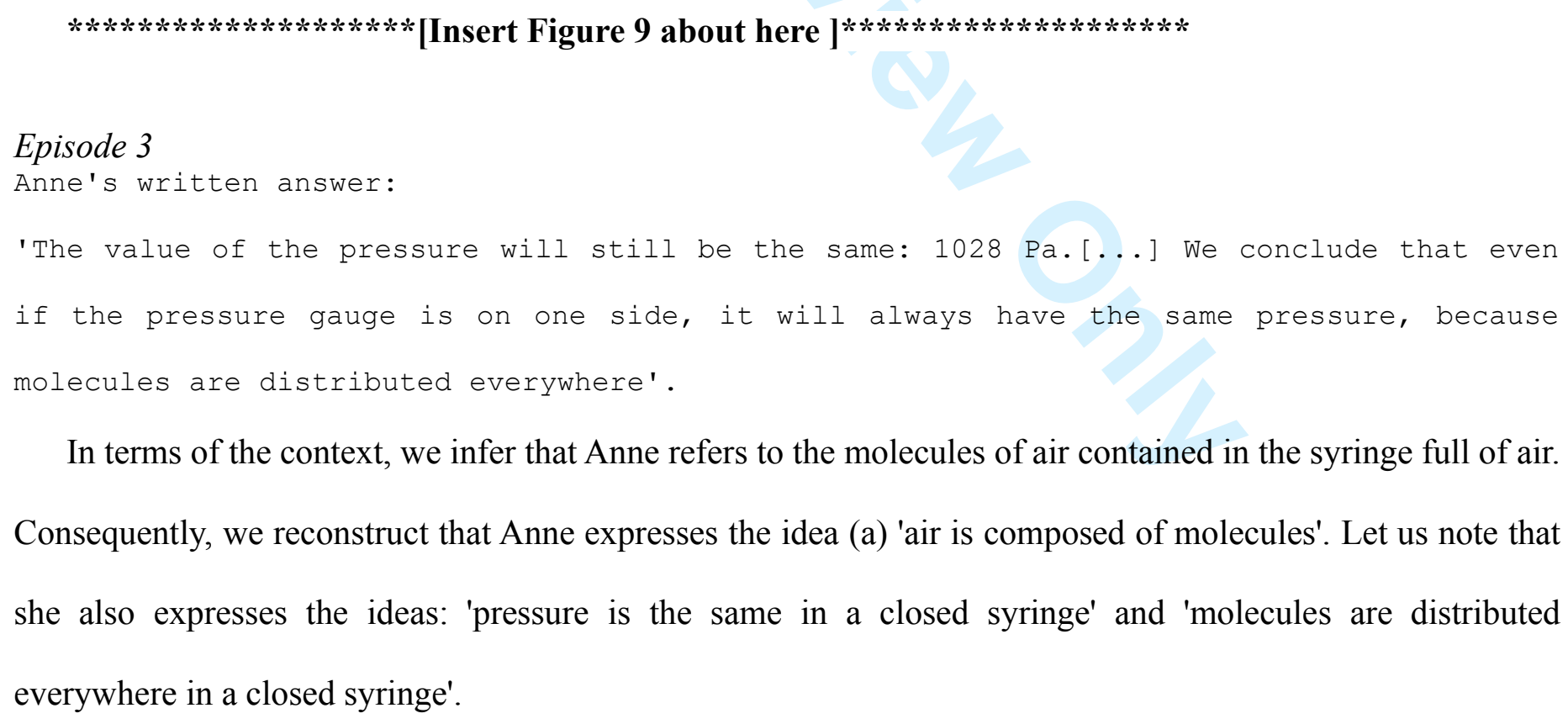

In terms of the context, we infer that Anne refers to the molecules of air contained in the syringe full of air. Consequently, we reconstruct that Anne expresses the idea (a) 'air is composed of molecules'. Let us note that she also expresses the ideas: 'pressure is the same in a closed syringe' and 'molecules are distributed everywhere in a closed syringe'. 
The process 'increasing the domain of applicability' appears when an idea (or a network of ideas) already applied in a specific situation, is expressed in one or several new situations. We illustrate this process across these three episodes. Our analysis shows how Anne expresses the same idea (a) in different modalities (discourse, drawing and written answer) in three different situations. Although our examples about the idea (a) are limited to 3 situations, our analysis in the whole teaching sequence shows that the domain of applicability of this idea is composed of a set of 13 situations for Anne and 12 situations for Ellen.

Our analysis of the domain of applicability of all the ideas and the network of ideas reconstructed during the entire teaching sequence (Table 2) shows that the process 'increase the domain of applicability of a network of ideas' works in the same way as the process 'increasing the domain of applicability of an idea'.

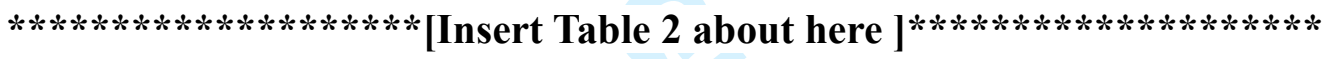

The first column of table 2 describes who voices the idea or the network of ideas. The second one specifies the name of the ideas or the network of ideas and the third column represents the number of situations for the domain of applicability in which the idea or the network of ideas is expressed.

In all, the process 'increasing the domain of applicability' is used 51 times by Anne (34 times with 7 ideas and 17 times with 5 networks of ideas) and 43 times by Ellen (29 times with 5 new ideas and 14 times with 4 networks of ideas). This process is used 94 times by both students, whereas the process of linking two ideas together appears only 19 times. Consequently, our results support the assertion: the process 'increasing the domain of applicability' is very often used by both students during the entire teaching sequence.

\section{Decreasing the domain of applicability}

In this section we discuss the process called 'decreasing the domain of applicability' of an idea (or network of idea). This process means that a student explicitly realises that an idea or a network of ideas (already expressed in a situation) is not appropriate for this situation and stops using it. Our video excerpts show that this process is rarely used by the two students during the teaching sequence. Here, we illustrate the process 
'decrease the domain of applicability of a network of ideas', and present our analysis of the students' use of this process during the teaching sequence.

\section{Case study 3: decrease the domain of applicability of a network of ideas}

Anne decreases the domain of applicability of a network of ideas about the macroscopic variables: pressure and volume (shown as $\mathrm{V}$ increases $<=>\mathrm{P}$ increases). This can be seen in episodes 1 and 2 , involving four students called Anne, Ellen, Adele and Marie during the second question of activity $\mathrm{n}^{\circ} 1$ of the fifty minute lesson called Cours $\mathrm{n}^{\circ} 2$ (figure 10).

\section{$* * * * * * * * * * * * * * * * * * * *[$ Insert Figure 10 about here $] * *$}

The situation is composed of: (1) question $\mathbf{n}^{\circ} \mathbf{2}$ : 'Experimentally, we try to find the relationship between the pressure and the volume to answer how the amount of pressure inside a syringe connected to a pressure gauge evolves, when the volume increases?' and (2) experimental equipment: a syringe connected to a pressure gauge.

Episode 1 happens when students begin to read question 2, whereas episode 2 occurs when students start to change the volume of the syringe connected to the pressure gauge.

\section{Episode 1:}

In this episode, Adele is reading the question out loud (turn 01) when Anne explains to the other students in her group that if the volume increases twice over, the pressure will increase to twice as much (turn 02). With regard to the context, we consider through her explanation, that Anne establishes a link between the increase in the volume of the syringe and the increase of the air pressure into the syringe. We interpret this link as the network of ideas $n^{\circ} 9$ : $^{V}$ increases $<=>$ P increases'. 
Four minutes later in the same situation (same question and same experimental equipment), Anne starts to increase the volume of the syringe connected to the pressure gauge, when Marie and Adele are still to draw up the table in which they will write the value of the volume with regard to the pressure (episode 2).

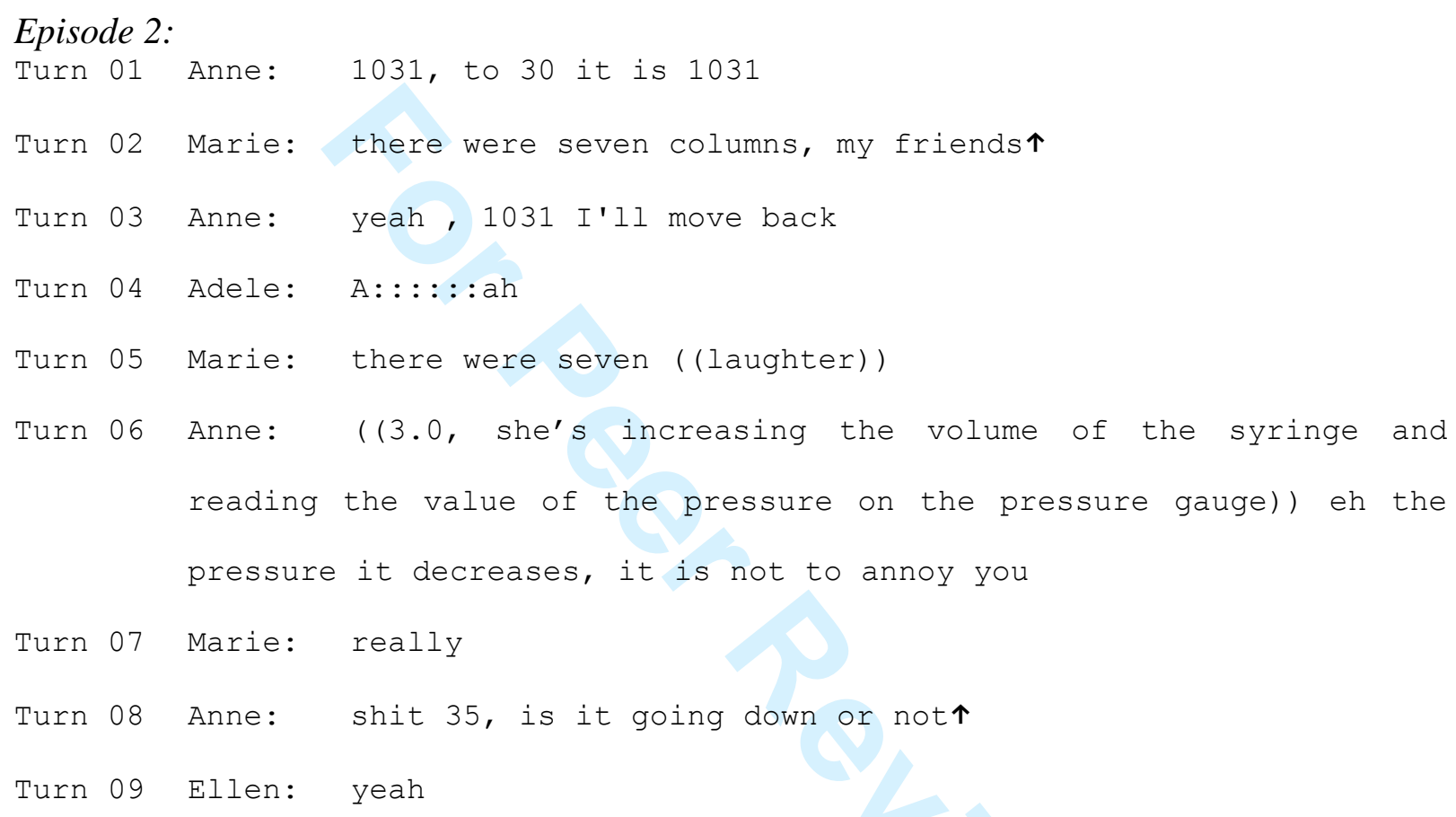

Anne says the value of the volume and the pressure to allow other students in the group to write these values in the table. She specifies that the value of the volume is ' 30 ', when the value of the pressure is '1031' (turn 01). Marie asks if the table is composed of seven columns (turn 02). Anne answers affirmatively to Marie and starts to move the syringe piston back (turn 03). Then, Adele yells: 'A::::ah' because she forgets a column, and Marie laughs at her by reminding her that there were seven columns (turn 04 and 05). Anne is increasing the volume of the syringe by moving back the piston, when she says to the group: 'eh the pressure it is decreasing' (turn 06). By simultaneously doing these two things, we consider that Anne establishes a new link between the volume of the syringe (which increases) and the air pressure into the syringe (which decreases). We interpret this new link with the network of ideas (8): ' $\mathrm{V}$ increases $<=>\mathrm{P}$ decreases'. Marie seems to be surprised by this new link by saying 'really' ( 07). Then, Anne seems to doubt this, and she asks if the 
pressure (referred to with the term 'that') diminishes or not, when the value of the volume is '35' (turn 08). Ellen confirms to Anne that the pressure decreases by saying 'yeah ' (turn 09).

The analyses of episodes 1 and 2 illustrate what 'decrease the domain of the applicability' means. We specify that both episodes happen in the same situation defined by question $\mathrm{n}^{\circ} 2$ and the experimental equipment composed of a syringe connected to a pressure gauge (see above). In episode 1, Anne uses the network of ideas $n^{\circ} 9$ : ' $V$ increases $<=>P$ increases'. This network considers that the pressure into an enclosed syringe increases when the volume of the syringe increases. Four minutes later during episode 2, Anne realises that the pressure decreases when the volume of the syringe increases (shown by the network $n^{\circ} 8$ 'V increases $<=>P$ decreases'). Then, she stops using the network of ideas $n^{\circ} 9^{\prime} V$ increases $<=>P$ increases' until the end of the question. Furthermore, she never re-uses the network $n^{\circ} 9$ until the end of the teaching sequence. This micro change is supported simultaneously by (a) an experiment (i.e. the value on the pressure gauge when the volume of the syringe increases) and (b) social interaction (i.e. when Ellen confirms to Anne that the value of the pressure decreases during the volume increase ).

More generally, 'decreasing the domain of applicability' means that a person realises explicitly that an idea or a network of ideas (already expressed in the situation) is not appropriate for this situation and stops using it. Consequently, the set of situations, in which this idea (or network of ideas) is applied, decreases.

Now, we are going to present students' ideas and networks of ideas, which have decreased their domain of applicability during the teaching sequence (Table 3).

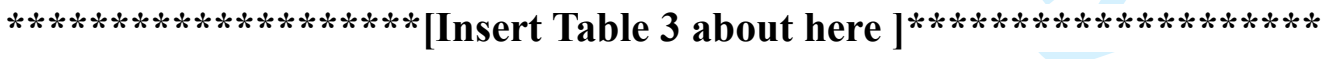

Table 3 gives the decrease of the domain of applicability of two networks of ideas expressed by Anne and one idea applied by Ellen. In all, this process is used by both students only 3 times during the entire teaching sequence. That confirms the assertion that: the process to 'decrease the domain of applicability' is rarely used by the students during the teaching. 
Previous studies on students' conceptions and conceptual change have shown that similar ideas and networks of ideas are currently used by students. Anne's network of ideas $n^{\circ} 5$ seem to be very close to Ohm's P-prim: 'more effort implies more result' (DiSessa, 1993), interpreted as: a bigger volume in the syringe implies a larger quantity of air. Ellen's idea $\mathrm{n}^{\circ} \mathrm{m}$ : 'there is no air in an open bottle' is very similar to the 'air without movement does not exist' (Séré, 1985).

These ideas and networks of ideas could be considered as inconsistent from the a physics point of view judging that they are applied outside of their domain of validity. Indeed, Anne said that the quantity of air into a closed syringe increases, when the volume increases (network $n^{\circ} 5$ ); whereas physics considers that the quantity is still the same, because a closed syringe is airtight. Similarly, Ellen said that there is no air in an open bottle, whereas physics considers that an open bottle is full of air. However, the process 'decreasing the domain of applicability' can be applied to consistent ideas as well as inconsistent ideas from a physics perspective. Indeed, this process necessitates that the student realises when an idea or a network of ideas is inconsistent (from her/his own point of view) with regard to the situation and stops using it. Although this process is used by both students only on inconsistent (from a physics point of view) ideas or networks of ideas, it could be also be applied to consistent (from the physics point of view) ideas or networks of ideas which are inconsistent with the situation from the student's point of view.

\section{Discussion}

Our study offers a description of the learning development of two students based on three processes: (1) 'establishing a link between ideas', (2) 'increasing the domain of applicability' and (3) 'decreasing the domain of applicability'. To identify these processes, we first reconstructed all ideas about gas expressed by both students in the entire teaching sequence. Our methodological approach tries to reconstruct the meaning given by students based on relevant semiotic resources (meaning-making) in oral (i.e. talk, gesture, salient elements of the setting) and written communication (i.e. text, drawing, graph, formula etc.). To reconstruct students' 
ideas, we adopt students' point of view, by avoiding assessing them as 'correct' or 'incorrect' based on scientific points of view.

Our results show that both students use: the process 'increasing the domain of applicability' 94 times (51 times by Anne and 43 times by Ellen), the process called 'establishing a link between ideas' 19 times (11 times by Anne and 8 times by Ellen) and the process 'decreasing the domain of applicability' 3 times (Twice by Anne and once by Ellen) during the teaching sequence about gas behaviour. These results show that each student uses each of the three processes approximately the same amount of times. Indeed, the process 'increasing the domain of applicability' is used on average 47 times by each student, the process 'establishing a link between ideas' is used on average 9.5 times by each student and the process 'decreasing the domain of applicability' is applied on average 1.5 times. In the same way, each student more often establishes links between two ideas (approximately 8 times) than between three ideas (approximately 1.5 times). Furthermore, the emergence of the networks of three ideas is supported by a network of two ideas previously spoken about during the teaching sequence.

These results only concern two students (Anne and Ellen) during the specific teaching sequence about gas. They cannot be extrapolated to other students or in other teaching sequences. However, they can be: (a) compared with results of previous studies and (b) considered as assumptions which will be tested in new studies.

A previous study analysed in great detail 27 German students (grade 11) working on physics tasks (Aufschnaiter \& Aufschnaiter, 2003). It proposed ten levels of complexity regrouped into four area to describe students' learning. One level of complexity of Area III is about the co-variation between two variables. This level of complexity seems very similar to our description in terms of a network of two ideas. E.g. the network of ideas $n^{\circ} 8$ : pressure of air decreases into a closed syringe when the volume increases (Table 1) can be considered as a co-variation between the macroscopic variables: pressure and volume. In the same way, the 
higher level of complexity (pertaining to Area IV) is about co-variations of more than two variable properties. This level of complexity seems very similar to our description of the network of three ideas. E.g., Anne's network of three ideas $\mathrm{n}^{\circ} \mathrm{I}$ (described episode 1 of the first case study) linked the variation of three variable properties: volume decreases, quantity is identical and the number of molecules is identical. In short , Aufschnaiter \& Aufschnaiter (2003) describe the links between the ideas with the notion of complexity in a very similar way. Furthermore, they found similar results regarding networks of three ideas. Indeed, the highest level of complexity (corresponding to a network of three ideas) is rarely found among the 27 students in grade 11 and the university students in their first semester. Although this study seems to confirm our results about the use of networks of three ideas, it does not come up with any results about the emergence of the networks of three ideas supported by networks of two ideas previously expressed. Consequently, we actually consider this result as an assumption, which has to be tested in other studies.

Concerning our results regarding the processes: increasing and decreasing the domain of applicability, the comparison with previous studies does not appear obvious. Indeed, as noted by Aufschnaiter \& Aufschnaiter (2003), the term 'situation' is used in very different ways in studies about learning, for example in situated cognition it is not clear whether: one situation is associated to the place (for example, calculation within the classroom or the supermarket (Lave, 1997)); or if every lesson is a different situation (Brown, Collins, and Duguid, 1989); or if every individual after a period of at least 3 seconds is in a new situation (Aufschnaiter \& Aufschnaiter, 2003); etc. Depending on the definitions of situations, the processes 'increasing' and 'decreasing' the domain of applicability could be described in radically different ways. For example, the process 'increasing the domain of applicability' might be used only 6 times during our teaching composed of 6 lessons based on the definition that 'every lesson is a different situation', whereas it could probably appear more than a thousand times based on a definition which considers that every individual is in a new situation after a period of 3 seconds. Consequently our results have to be tested in other studies adopting our definition of a situation. 
Our results on the involvement of the three processes are consistent only to the two students during the specific teaching sequence on gas. These preliminary results need to be tested as assumptions in our complete database composed of video recordings of fourteen students, who have done the same teaching learning about gas. This first step will allow us to study the use of the three processes by different students in greater depth. The second step will be to test our assumptions in other sets of data, e.g. teaching sequences on mechanics or electricity. The aim is to determine whether the use of the three processes depends only on the teaching sequence on gas or if some uses of these processes could be considered as being how students generally work, which could be used independently from the domain of taught physics. For example, causal reasoning (Tiberghien, 2004; Viennot, 2001) or ohm's p-prims (DiSessa, 1993) are used in many areas of physics.

Finally, our present study focuses on only three processes, whereas learning involves many processes. Some of them have be identified and studied by previous research studies (see theoretical framework) and others will be found out by future studies. All of these research studies should carefully analyse whether and how elements of the teaching sequence could support the use of processes by students to have a better understanding of the teaching influences on students' learning.

\section{Coda}

Our preliminary results have implications not only to reconstruct in detail expressed ideas and analyse the use of the three processes during teaching, but also for the design of the teaching sequence and curriculum, which intend to take the learning processes into account.

Indeed, our first result shows that the emergence of the networks of three ideas needs networks of two ideas to express previously by students. Furthermore, the emergence of the network of two ideas could be supported by each idea (which constituted the network) expressed previously by students (see figure 5). If this result is to be applied to other students, we suggest designing teaching sequences which envisage a gradual set of tasks to facilitate the emergence of networks of three ideas. With this aim in mind, a first set of tasks will be 
designed to allow students to express the ideas on their own, beforehand. A second set of tasks will be set for students to establish links between two ideas. The last set of tasks will facilitate students' ability to talk about networks of three ideas based on the networks of two ideas previously expressed. This proposal concerns the way of designing teaching sequences about gas, but also the development of curricula. They should take into account the gradual aspect of the emergence of networks of ideas by giving instructions to help teachers. For example, by allocating more time to develop gradual sets of tasks which favour the links between ideas .

Our second result concerns the process 'increasing the domain of applicability', which is the one most called upon by students. This process is often developed implicitly by French teachers, by giving different exercises about the same scientific concept for homework. Consequently, we suggest designing teaching sequences in which the same scientific concepts will be involved systematically by students in several situations. Furthermore, we consider that this learning process should be explicitly assessed by teachers, to help students to have a better understanding of these aspects of their learning.

\section{Acknowledgments}

The authors thank the members of the team GESTEPRO at the University of Provence for their critical comments and feedback about this article.

\section{References}

Adey, P. (1999). Revisiting cognitive conflict, construction, and metacognition, and discovering metaconstructivism. In M. Komorek, Behrendt, H., Dahncke, H. , Duit, R., Graeber, W. , Kross, A. (Ed.), Research in Science Education - Past, Present, and Future Vol.1 (pp. 58-61). Kiel: IPN Kiel.

Aufschnaiter, C. v., \& Aufschnaiter, S. v. (2003). Theoretical framework and empirical evidence of students' cognitive processes in three dimensions of content, complexity, and time. Journal of Research in Science Teaching, 40(7), 616-648. 
Balacheff, N. (1995). Conception, connaissance et concept. In D. Grenier (Ed.), Séminaire Didactique et Technologies cognitives en mathématiques (pp. 219-244). Grenoble: IMAG.

Balacheff, N., \& Gaudin, N. (2009). Modeling students conceptions (the case of functions) Research in Collegiate Mathematics Education (Vol. 16, pp. 183-211). Washington: American Mathematical Society.

Benson, D. L., Wittrock, M. C., \& Baur, M. E. (1993). Students' preconceptions of the nature of gases. Journal of Research in Science Teaching, 30(6), 587-597.

Brook, A., Briggs, H., \& Driver, R. (1984). Aspects of secondary students' understanding of the particulate nature of matter. Leeds: University Leeds, centre for Studies in Science and Mathematics Education.

Brown, D. E., \& Hammer, D. (2008). Conceptual change in physics. In S. Vosniadou (Ed.), International handbook of research on conceptual change (pp. 127-155). New York: Routledge.

Brown, J. S., Collins, A., \& Duguid, P. (1989). Situated Cognition and the Culture of Learning. [A]. Educational Researcher, 18, 32-42.

Caravita, S., \& Hallden, O. (1994). Re-framing the problem of conceptual change. Learning and Instruction, 4, 89-111.

Chi, M. T. H. (2008). Three types of conceptual change: Belief revision, mental model transformation, and categorical shift. In S. Vosniadou (Ed.), International handbook of research on conceptual change (pp. 61-82). New York: Routledge.

Clement, J. (2008). The role of explanatory models in teaching for conceptual change. In S. Vosniadou (Ed.), International handbook of research on conceptual change (pp. 417-452). New York: Routledge.

Clough, E., \& Driver, R. (1986). A study of consistency in the use of students' conceptual frameworks across different task contexts. Science Education, 70(4), 24.

de Berg, K. C. (1992). Students' thinking in relation to pressure-volume changes of a fixed amount of air: the semi-quantitative context. International Journal of Science Education, 14(3), 295-303.

DiSessa, A. (1993). Towards an epistemology of physics. Cognition and Instruction, 2 (3), 105-225.

DiSessa, A. A. (1988). Knowledge in pieces. In G. Forman \& P. B. Pufall (Eds.), Constructivism in the computer age (pp. 49-70). Hilsdale NJ: Erlbaum. 
DiSessa, A. A. (2002). Why conceptual ecology is a good idea. In M. Limon \& L. Mason (Eds.), Reconsidering conceptual change: Issues in theory and practice (pp. 29-60). Dordrecht Kluwer.

DiSessa, A. A. (2008). A bird's-eye view of the "pieces" vs. "coherence" controversy (from the "pieces" side of the fence). In S. Vosniadou (Ed.), International handbook of research on conceptual change (pp. 35-60). New York: Routledge.

DiSessa, A. A., \& Sherin, B. L. (1998). What changes in conceptual change? International Journal of Science Education, 20(10), 1155-1192.

Duit, R., Goldberg, F. M., \& Niedderer, H. (1992). Research in physics learning: Theoretical issues and empirical studies. Kiel: IPN.

Duval, R. (1995). Sémiosis et pensée humaine. Registres sémiotiques et apprentissages intellectuels. Berne: Peter Lang.

Edwards, D. (1993). But What Do Children Really Think? Discourse Analysis and Conceptual Content in Children's Talk. Cognition and Instruction, 11(3), 207-225.

Gentner, D. (1983). Structure-mapping: A theoretical framework for analogy. Cognitive Science, 7, 155-170.

Givry, D. (2003). Etude de l'évolution des idées des élèves de seconde durant une séquence d'enseignement sur les gaz. Université Lumière, Lyon.

Givry, D., \& Roth, W.-M. (2006). Toward a new conception of conceptions: Interplay of talk, gestures, and structures in the setting. Journal of Research in Science Teaching, 43(10), 1086-1109.

Goodwin, C. (2000). Action and embodiment within situated human interaction. Journal of Pragmatics, 32 , 1489-1522.

Gunstone, R., \& Mitchell, I. (1998). Metacognition and conceptual change. In J. Mintzes, J. Wandersee \& J. Novak (Eds.), Teaching science for understanding (pp. 133-163). San Diego: Academic Press.

Hatano, G., \& Inagaki, K. (1994). Young children's naive theory of biology. Cognition, 50, 171-188.

Hewson, P. W. (2008). Conceptions over time: Are language and the here-and-now up to the task? Cultural studies of science education(3), 263-276. 
Hewson, P. W., \& Hewson, M. G. (1992). The status of students' conceptions. In R. Duit, F. Goldberg \& H. Niedderer (Eds.), Research in physics learning: Theoretical issues and empirical studies (pp. 59-73). Kiel: IPN.

Holyoak, K., \& Thagard, P. (1989). A computational model of analogical problem solving. In S. Vosniadou \& A. Ortony (Eds.), Similarity and analogical reasoning (pp. 199-241). New York: Cambridge University Press.

Hutchins, E. (1995). Cognition in the Wild MIT Press.

Jordan, B., \& Henderson, A. (1995). Interaction analysis: Foundations and practice. The Journal of Learning Sciences, 4, 39-103.

Kerbrat-Orecchioni, C. (1996). La conversation. Paris: Mémo édition SEUIL.

Kerguelen, A. (Producer). (2001) Kronos.

Lave, J. (1997). The Culture of Acquisition and the Practice of Understanding. In D. Kirschner \& J. Whitson (Eds.), Situated cognition: social, semiotic, and psychological perspectives (pp. 17-35). Mahwah, NJ: Lawrence Erlbaum Associates.

Lave, J., \& Wenger, E. (1991). Situated Learning: Legitimate Peripheral Participation. Cambridge Cambridge University Press.

Lemke, J. K. (1990). Talking science. Norwood, NJ: Ablex.

McNeill, D. (1985). So you think gestures are nonverbal? Psychological Review, 92, 350-371.

Meheut, M., \& Chomat, A. (1990). The bounds of children's atomism: An attempt to make children build up a particulate model of matter. In P. L. Lijnse, P. Licht, W. Vos \& A. J. Waarlo (Eds.), Relating macroscopic phenomena to microscopic particles: a central problem in secondary Science Education (pp. 266-282). Utrecht: CD-ß Press.

Méheut, M., Larcher, C., Chomat, A., \& Barboux, M. (1988). Modèles particulaires et activités de modélisation au collège. In G. Vergnaud (Ed.), Didactique et acquisition des connaissances scientifiques (pp. 201-216). Grenoble La Pensée Sauvage. 
Minstrell, J. (1992). Facets of students' knowledge and relevant instruction. In R. Duit, F. Goldberg \& H. Niedderer (Eds.), Research in physics learning: Theoretical issues and empirical studies (pp. 110128). Kiel: IPN.

Miyake, N. (2008). Conceptual change through collaboration. In S. Vosniadou (Ed.), International handbook of research on conceptual change (pp. 453-478). New York: Routledge.

Niedderer, H., Goldberg, F. M., \& Duit, R. (1992). Towards learning process studies: A review of the workshop on research in physics learning. In R. Duit, Goldberg, F. , Niedderer, H. (Ed.), Research in physics learning: Theoretical issues and empirical studies (pp. 10-28). Kiel: IPN.

Novick, S., \& Nussbaum, J. (1978). Junior High School pupils' understanding of the particulate nature of matter: An interview study. Science Education, 62, 273-281.

Petri, J., \& Niedderer, H. (1998). A learning pathway in high-school level quantum physics. International Journal of Science Education, 20(9), 1075-1088.

Pfundt, H., \& Duit, R. (2010). Bibliography: Students' and teachers' conceptions and science education. Kiel:: IPN.

Pintrich, P. R. (1999). Motivational beliefs as resources for and constraints on conceptual change. In W. Schnotz, Vosniadou, S. , Carretero, M. (Ed.), New perspectives on conceptual change (pp. 33-50). Oxford, UK: Pergamon.

Pintrich, P. R., Marx, R. W., \& Boyle, R. A. (1993). Beyond cold conceptual change: The role of motivational beliefs and classroom contextual factors in the process of conceptual change. Review of Educational Research, 63(2), 167-199.

Posner, G. J., Strike, K. A., Hewson, P. W., \& Gertzog, W. A. (1982). Accommodation of a scientific conception: Toward a theory of conceptual change. Science Education, 66(2), 211-227.

Reiss, M. J., \& Tunnicliffe, S. D. (2001). Students' understandings of human organs and organ systems. Research in Science Education, 31(3), 383-399.

Saljo, R. (1999). Concepts, cognition and discourse: from mental structures to discursive tools. In W. Schnotz, S. Vosniadou \& Carretero (Eds.), New perspectives on conceptual change (pp. 81-90). Oxford: Pergamon. 
Séré, M. G. (1985). The gaseous state. In R. Driver, E. Guesne \& A. Tiberghien (Eds.), Children's ideas in science (pp. 104-123). Milton Keynes: Open University Press.

Sinatra, G. M., \& Mason, L. (2008). Beyond knowledge: Learner characteristics influencing conceptual change. In S. Vosniadou (Ed.), International handbook of research on conceptual change (pp. 560582). New York: Routledge.

Smith, J. P., DiSessa, A., \& Roschelle, J. (1994). "Misconceptions reconceived: a constructivist analysis of knowledge in transition". Journal of the Learning Sciences, 3(2), 115-163.

Stavy, R. (1988). Children's conception of gas. International Journal of Science Education, 10(5), 553-560.

Strike, K. A., \& Posner, G. J. (1992). A revisionist theory of conceptual change. In R. A. Duschl \& R. Hamilton (Eds.), Philosophy of science, cognitive science, and educational theory and practice (working title) (pp. 1-20). Albany, NY: SUNY Press.

Tiberghien, A. (1994). Modeling as a basis for analyzing teaching-learning situations. Learning and Instruction, 4, 71-87.

Tiberghien, A. (2000). Designing teaching situations in the secondary school. In R. Millar, Leach, J. , Osborne, J. (Ed.), Improving science education (pp. 27-47). Buckingham: Open University Press.

Tiberghien, A. (2004). Causalité dans l'apprentissage des sciences. Intellectica, 38(1), 69-102.

Tiberghien, A., Vince, J., \& Gaidioz, P. (2009). Design-based Research: Case of a teaching sequence on mechanics. International Journal of Science Education, 31(17), 2275 - 2314.

Viennot, L. (2001). Reasoning in Physics. The Part of Common Sense: Kluwer Academic Publishers.

Vosniadou, S. (1994). Capturing and modelling the process of conceptual change. Learning and Instruction, $4(1), 45-69$.

Vosniadou, S. (2003). Exploring the relationships between conceptual change and intentional learning. In G. M. Sinatra \& P. R. Pintrich (Eds.), Intentional conceptual change (pp. 377-406). Mahwah, NJ: Erlbaum.

Vosniadou, S., \& Brewer, W. F. (1992). Mental models of the earth: a study of conceptual change in childhood. Cognitive Psychology, 24, 535-585. 
Vosniadou, S., Vamvakoussi, X., \& Skopeliti, I. (2008). The framework theory approach to the problem of conceptual change. In S. Vosniadou (Ed.), International handbook of research on conceptual change (pp. 3-34). New York: Routledge.

White, R. T. (1993). Insights on conceptional change derived from extensive attempts to promote metacognition. Paper presented at the annual meeting of the American Educational Research Association, Atlanta, 1-15.

Wiser, M., \& Carey, S. (1983). When heat and temperature were one. In D. Gentner \& A. L. Stevens (Eds.), Mental models (pp. 267-297). Mahwah, NJ: Lawrence Erlbaum.

Wiser, M., \& Smith, C. L. (2008). Learning and teaching about matter in grades K-8: When should the atomic-molecular theory be introduced. In S. Vosniadou (Ed.), International handbook of research on conceptual change. New york: Routledge.

Zembylas, M. (2005). Three perspectives on linking the cognitive and the emotional in science learning: Conceptual change, socio-constructivism and poststructuralism. Studies in Science Education, 41, 91116. 


\section{Captions}

Figure 1: Cameras' position in the classroom during TP lessons with group of 2 students: Black circle represents the teacher, white circles represent students and the grey circle represents the researcher behind camera 3.

Figure 2: Cameras' position in the classroom during Cours lessons with a group of 4 students: Black circle represents the teacher, White circles represent students and the grey circle represents the researcher behind camera 3 .

Figure 3: How lesson TP $n^{\circ} 1$ proceeds over one hour and eleven minutes

Figure 4: Draw a small amount of air in the syringe with the same mass in two cases: in a closed syringe without any action (case 1) and air in a closed syringe when we push the piston (case 2)

Figure 5: Emergence of the network of three ideas during the lesson TP $n^{\circ} 1$

Figure 6: Increasing the domain of applicability of the idea (a) by expressing it in the new situations 2 and 3.

Figure 7: Anne and Ellen's drawings to answer question $n^{\circ} 2$

Figure 8: Small amounts of air and red gas contained in two flasks in two cases: (1) separated by a wall and (2) connected

Figure 9: Drawing of the specific connection between syringe and pressure gauge

Figure 10: Development of the fourth lesson of fifty minutes called Cours $n^{\circ}$. 


\section{Figures}

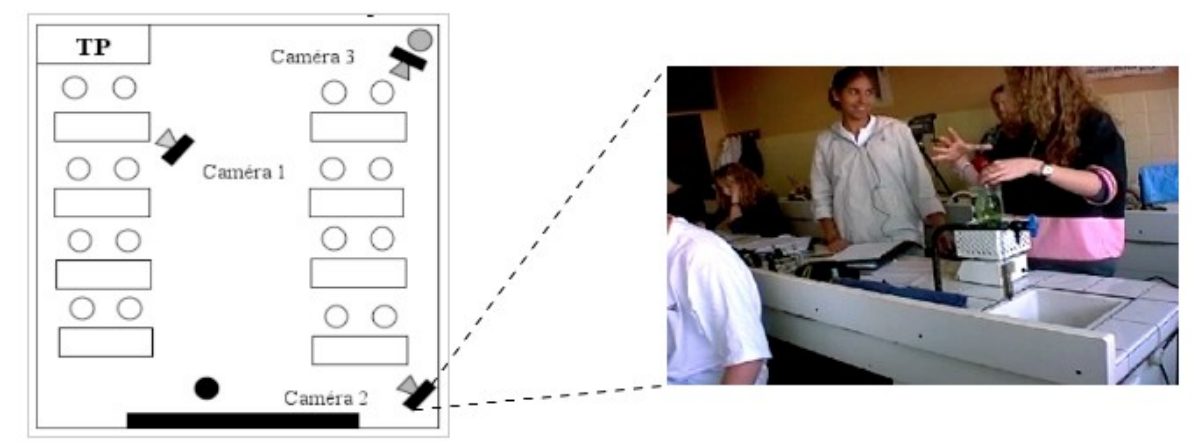

Figure 1 


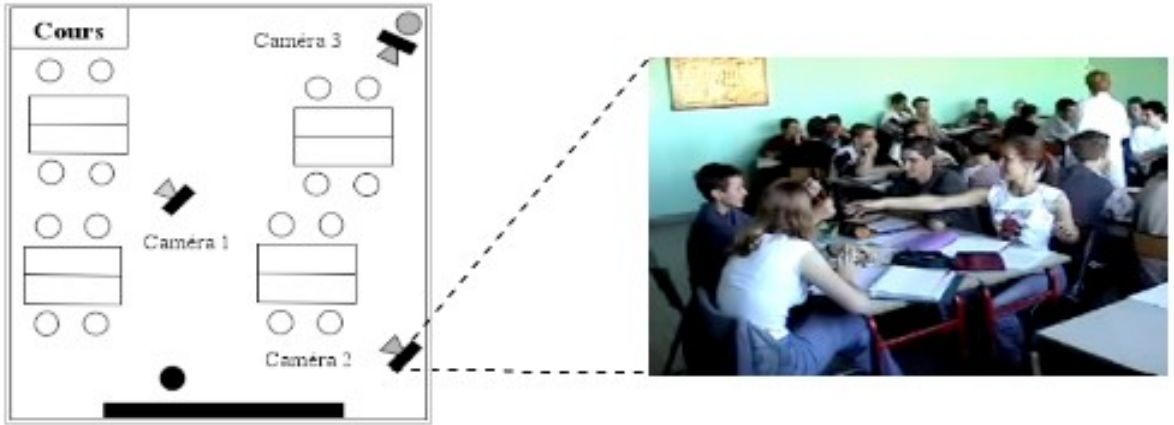

Figure 2 


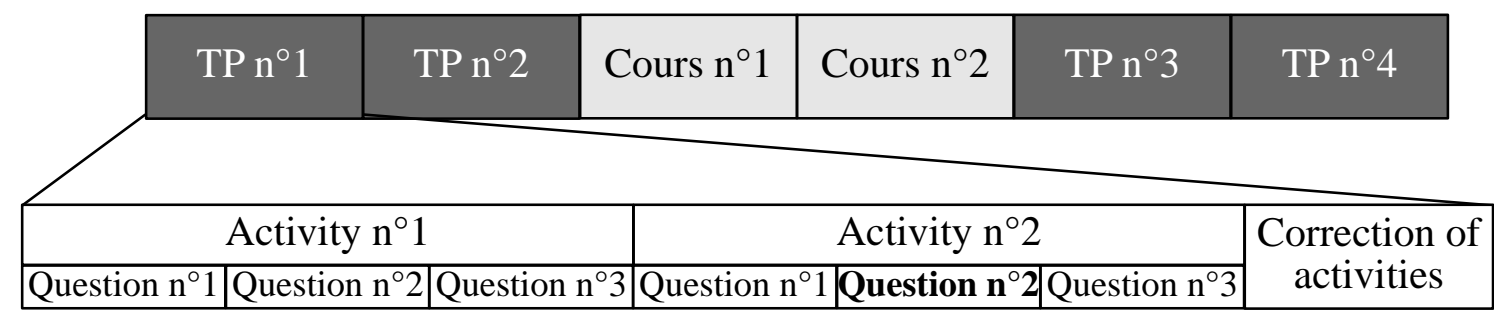

Figure 3 


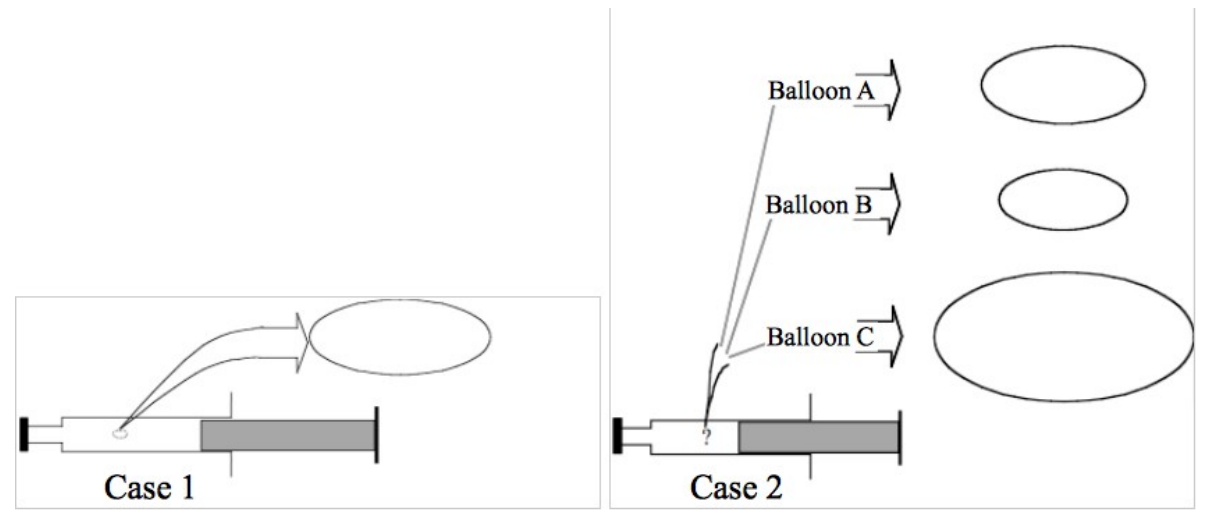

Figure 4 

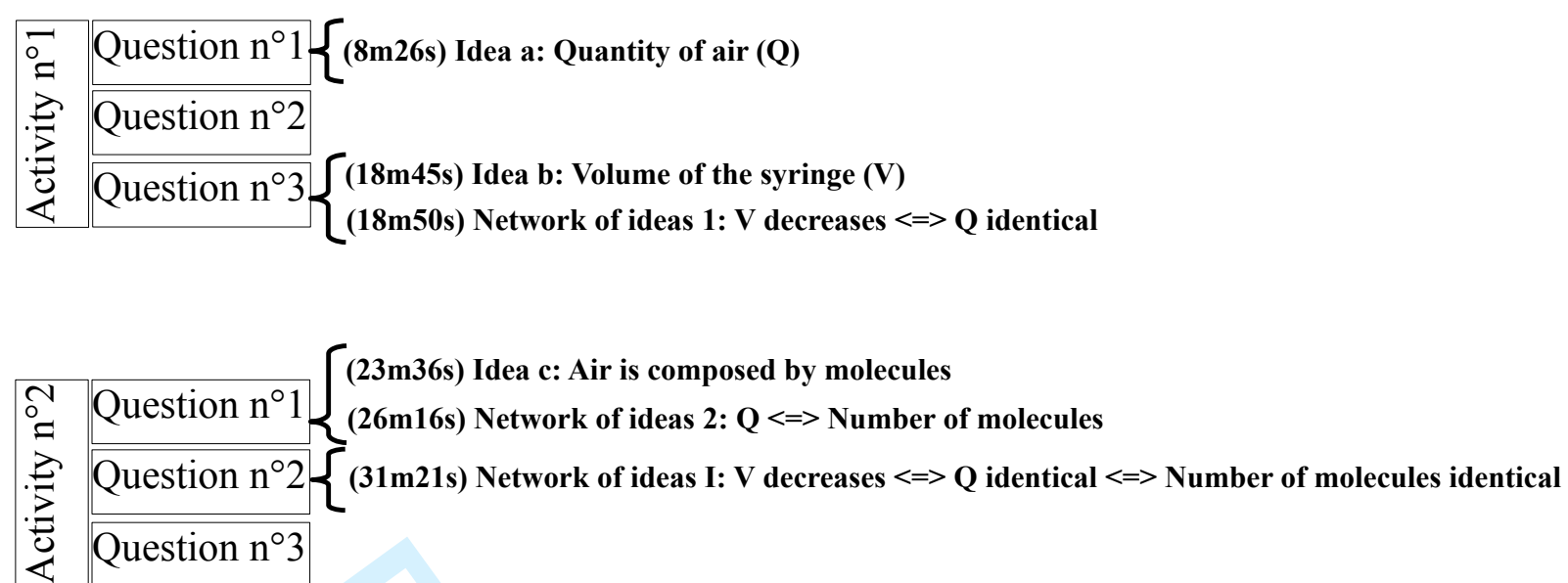

Figure 5 


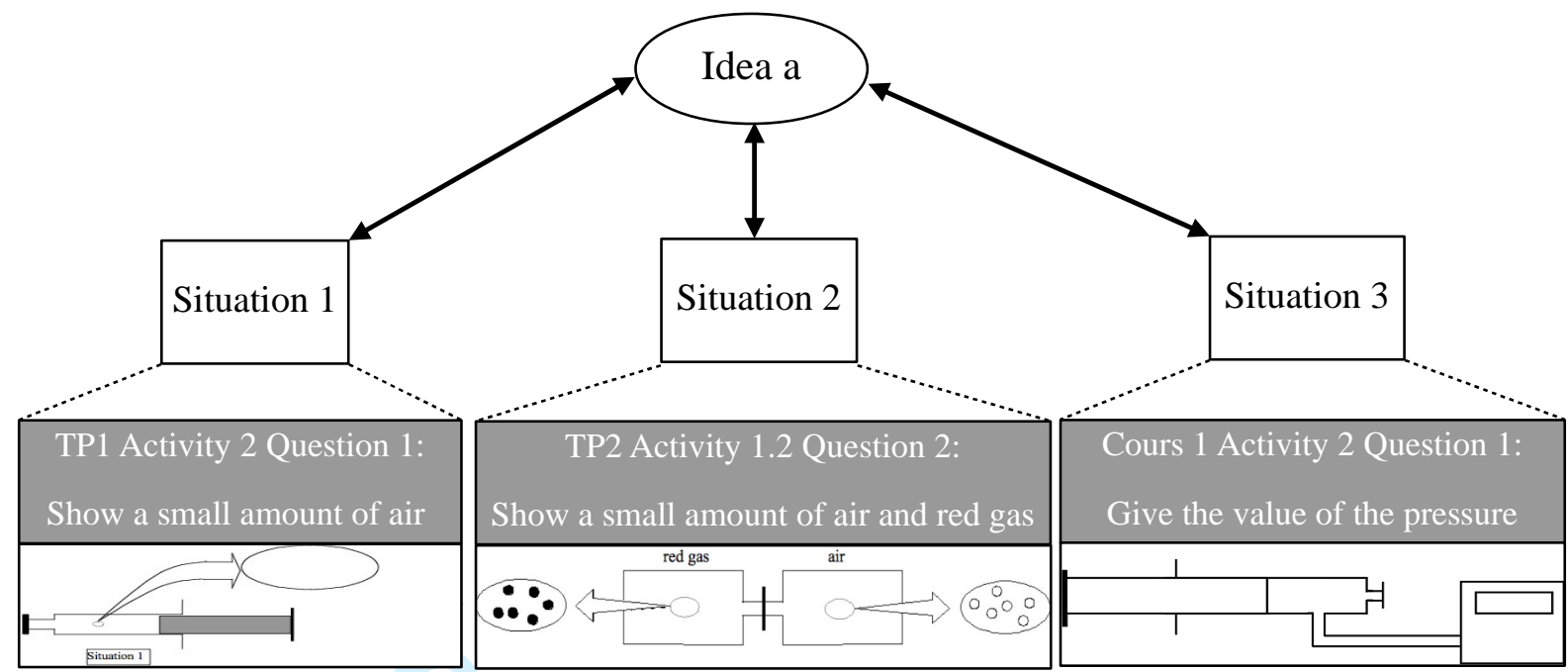

Figure 6 


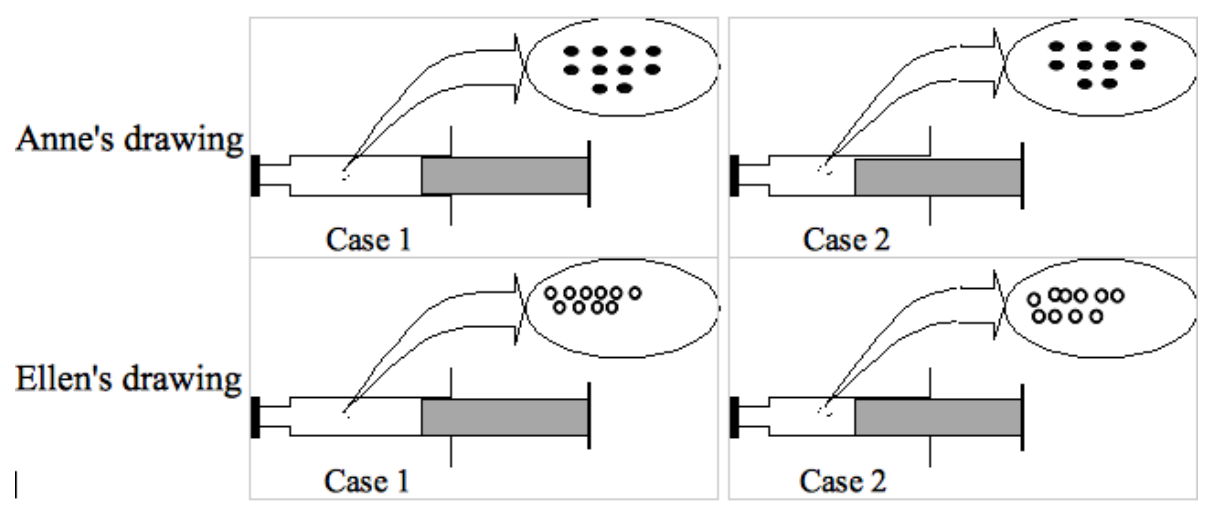

Figure 7 


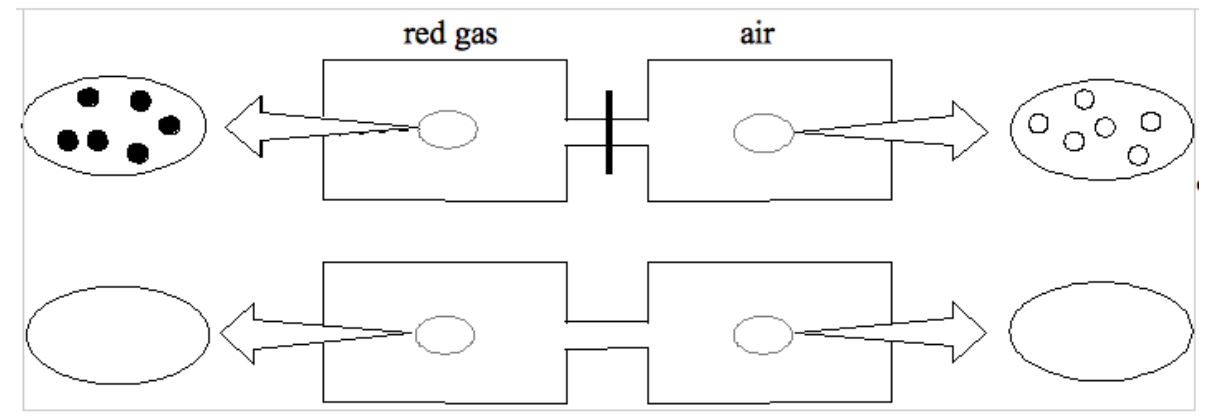

Figure 8 


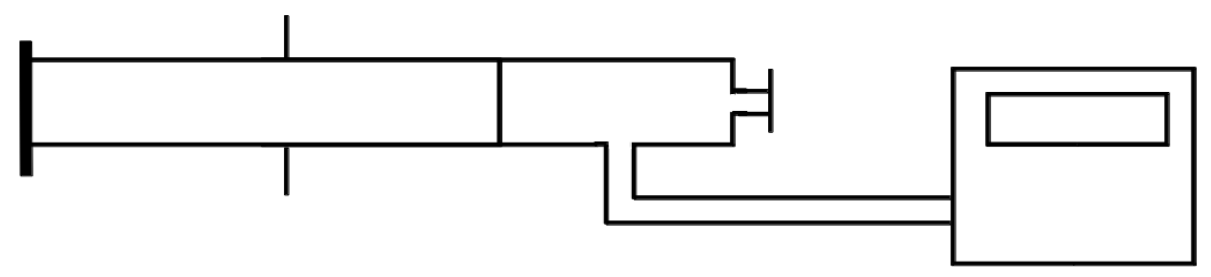

Figure 9 


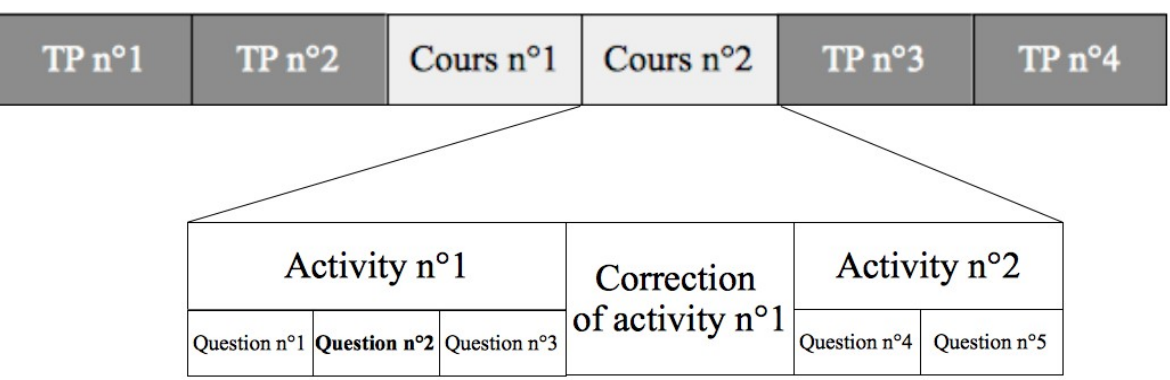

Figure 10 


\section{Captions}

Table 1: networks of ideas reconstructed by researchers during the entire teaching sequence

Table 2: Domains of applicability for all the ideas and networks of ideas expressed by Anne and Ellen during the entire teaching on gas.

Table 3: Decreasing the domain of applicability of idea or networks of ideas. 


\section{Table}

\begin{tabular}{|c|c|}
\hline $\begin{array}{l}\text { Student(s): } \\
\text { Anne or Ellen }\end{array}$ & Network of Ideas \\
\hline A & I. Volume decreases $<=>$ Quantity is identical $<=>$ Number of molecules is identical \\
\hline A \& E & 1. Volume decreases $<=>$ Quantity is identical \\
\hline A \& E & 2. Quantity $<=>$ Number of molecules \\
\hline E & II. Temperature increases $<=>$ Pressure increases $<=>$ Shocks of molecules increases \\
\hline A \& E & 3. Temperature increases $<=>$ Pressure increases \\
\hline A \& E & 4. Pressure $<=>$ Shocks of molecules \\
\hline A & III. Volume increases $<=>$ Number of molecules increases $<=>$ Molecules take up more space \\
\hline A & 5. Volume increases $<=>$ Quantity increases \\
\hline A & 6. Temperature increases $<=>$ Molecules accelerate \\
\hline A \& E & 7.Pressure increases $<=>$ Action of air increases \\
\hline A \& E & 8.Pressure decreases $<=>$ Volume increases \\
\hline A \& E & 9. Pressure increases $<=>$ Volume increases \\
\hline
\end{tabular}

Table 1 


\begin{tabular}{|c|c|c|}
\hline $\begin{array}{l}\text { Student(s): } \\
\text { Anne or Ellen }\end{array}$ & Ideas & $\begin{array}{c}\text { Domain of Applicability } \\
\text { (number of situations) }\end{array}$ \\
\hline$A \& E$ & a. Air is composed of molecules & $\begin{array}{l}\text { Anne: } 13 \\
\text { Ellen: } 12 \\
\end{array}$ \\
\hline$A \& E$ & $\begin{array}{l}\text { b. The word pressure is used with the physical meaning, i.e. } \\
\text { 'a variable to describe gas state' }\end{array}$ & 9 \\
\hline $\mathrm{A} \& \mathrm{E}$ & c. Air acts on the inner surfaces & 3 \\
\hline$A \& E$ & $\begin{array}{l}\text { d. The word pressure is used with the everyday meaning, } \\
\text { i.e. 'act of pushing' }\end{array}$ & 3 \\
\hline $\mathrm{A} \& \mathrm{E}$ & e. Molecules are distributed everywhere & 2 \\
\hline A & f. There is air in an open bottle & 2 \\
\hline A & g. Molecules are stuck to the inner surfaces of a syringe & 2 \\
\hline \multicolumn{3}{|c|}{ Network of Ideas } \\
\hline $\mathrm{A} \& \mathrm{E}$ & 2. Quantity $<=>$ Number of molecules & 5 \\
\hline $\mathrm{A} \& \mathrm{E}$ & 1. Volume decreases $<=>$ Quantity is identical & 4 \\
\hline A\&E & 4. Pressure $<=>$ Shocks of molecules & 3 \\
\hline $\mathrm{A}$ & 5. Volume increases $<=>$ Quantity increases & 3 \\
\hline $\mathrm{A} \& \mathrm{E}$ & 7. Pressure decreases $<=>$ Volume increases & 2 \\
\hline
\end{tabular}

Table 2 


\begin{tabular}{|cl|}
\hline $\begin{array}{c}\text { Students: } \\
\text { Anne or Ellen }\end{array}$ & $\begin{array}{c}\text { Decreasing the domain of applicability } \\
\text { of Idea or Network of ideas }\end{array}$ \\
\hline $\mathrm{A}$ & Network of ideas $n^{\circ} 5:$ V increases $<=>Q$ increases \\
\hline $\mathrm{A}$ & Network of ideas $n^{\circ} 6:$ V increases $<=>$ P increases \\
\hline $\mathrm{E}$ & Idea $n^{\circ} \mathrm{m}:$ There is no air in an open bottle \\
\hline
\end{tabular}

Table 3 